\title{
Late Presentation of a Disorder of Sexual Development Due to Rare 46XX/47XX SRY-Positive 46XX/47XX Karyotype
}

\author{
Elamin Ibrahim Elamin Abdelgadir ${ }^{1 *}$, Alaaeldin MK Bashier ${ }^{1}$, Fatheya Alawadi', Rashid Mustafa ${ }^{1}$, Suada AM Makeen ${ }^{3}$, Ali S Alzahrani ${ }^{2}$ and \\ Mohamed Abdelatif Elsayed ${ }^{1}$
}

${ }^{1}$ Endocrine Unit, Dubai Hospital, Alkhaleej road, Dubai, P.O.BOX: 7272, United Arab Emirates

${ }^{2}$ King Faisal Specialist Hospital and Research Centre, Riyadh, United Arab Emirates

${ }^{3}$ Medical officer in Ministry of Health, Sudan

\begin{abstract}
Genital tract differentiation and development is a complex process beginning early in embryonic life. Mutation or translocation of the sex-determining region of the $Y$ chromosome (SRY) may lead female genotype to become a male. The absence or genetic mutation of the SRY leads to a male phenotype individual but a female genotype individual (46xx), which is labeled as a Disorder of Sex Development (DSD). We are presenting an 18-year-old male who presented to the endocrine clinic with delayed puberty. There was no apparent predisposing factor upon review of his natal, childhood, and recent history. He had a no secondary sexual characteristics; stretched penile size was $5 \mathrm{~cm}$, and the volume of both testes was around $4 \mathrm{ml}$. Biochemical assessment showed Hypergonadotrophic hypogonadism, while the peripheral blood Karyotyping showed SRY-positive 46XX/47XX DSD. This is the first reported case with SRY 46XX/47XX, although the somatic changes were not different from the rest of the genetic mutation. The spectrum of the DSD presentation is increasing in the population with time, which necessitates meticulous assessment in early infancy, and genetic screening whenever we suspect this condition. The threshold of suspicion of such diseases should be lower.
\end{abstract}

Keywords: Disorder of sex development; SRY gene mutation; Gynaecomastia

Abbreviations: DSD: Disorder of Sex Development; ALT: Alanine transaminase; AST: Aspartate Aminotransferase; CT: Computed Tomography; FISH: Fluorescence In Situ Hybridization Method; SRY: Sex-Determining Region Y

\section{Introduction}

Human sex differentiation is a complex process that starts early in embryologic life. The presence of a Y chromosome will determine whether the bipotential genital tract development cascade will proceed as male (prostate, testes, and male SRY-positive DSD external genital organs); otherwise, the genital tract will end up female, with ovaries, a uterus, and female external genitalia [1]. Unfortunately, sometimes chromosomal aberrations take place, placing sex determination in jeopardy [1]. Disorder of Sex Development (DSD) is a group of genetic diseases that manifest across a broad spectrum of ages, starting from the intrapartum period through early infancy up to the post-pubertal period when they present with infertility or delayed puberty.

The main drive of this genetic disarray is a defect of the SexDetermining Region Y (SRY), the gene that is responsible for the differentiation of the bipotential urogenital fold of the embryo [2]. The SRY mutation-affected male is phenotypically male while his genetic makeup is usually female (XX). Such persons are labeled as SRY 46XX males. When we add the Disorder of sex development, the full description becomes SRY 46XX DSD individual [2] 46XX individuals usually present at puberty, though approximately $10 \%$ present earlier with apparent ambiguous genitalia. The usual presentation is failure to attain puberty and/or infertility. Infertility is a universal feature in those cases, since the Azoospermia Factor gene (AZF), the germ cells gene differentiation, and development gene are located in the $\mathrm{Y}$ chromosome [3].

All reported cases, to our best knowledge, are 46XX DSD; we are presenting for the first time a DSD with a genetic label of SRY 46XX/47XX gene mutation (demonstrated by fluorescence in situ hybridization method).

\section{Case Presentation}

We are presenting an 18-year-old male who presented with no previous medical illnesses. He sought medical advice for a progressive increase in weight and failure to have secondary sexual characteristics. Mr. X noticed that he lacked secondary sexual characteristics (beard or mustache like his classmates). In reviewing Mr. X's history, his mother enjoyed an uneventful pregnancy and had a normal vaginal delivery. $\mathrm{He}$ accomplished all normal developmental milestones, and he is currently in secondary school, where he is performing well. He denied having mumps in his childhood; there is no history of trauma or exposure to radiation. Currently he does not have any sexual desire for the other gender and no morning erections; he noticed that his genitalia is small, and there is no hair at all in the groin and the axillary areas. His voice is still not masculinized. He denied taking any medications; he neither smokes nor consumes alcohol and is not taking any herbal products. There was no family history of similar medical problem, no history of ambiguous genetalia or hypospadias, and the parents are not blood related to each other (no parental consanguinity).

Upon physical examination, he was tall for his age with a Body Mass Index (BMI) of $33 \mathrm{Kg} / \mathrm{m}^{2}$. His blood pressure was $136 / 83$ and $132 / 79 \mathrm{mmHg}$ in the right and left arm, respectively; there were no secondary sexual characteristics appreciated (No beard, no mustache, no axillary or groin hair [Tanner score 1], and his muscle component was feminized). He had gynaecomastia that was not tender. His

*Corresponding author: Elamin Ibrahim Elamin Abdelgadir, Endocrine Unit, Dubai Hospital, Alkhaleej road, Dubai, P.O.BOX: 7272, United Arab Emirates; E-mail: alaminibrahim@hotmail.com

Received April 25, 2015; Accepted June 15, 2015; Published June 17, 2015

Citation: Abdelgadir EIE, Bashier AMK, Alawadi F, Mustafa R, et al. (2015) Late Presentation of a Disorder of Sexual Development Due to Rare 46XX/47XX SRY-Positive 46XX/47XX Karyotype. J Clin Case Rep 5: 541. doi:10.4172/21657920.1000541

Copyright: ( 2015 Abdelgadir EIE, et al. This is an open-access article distributed under the terms of the Creative Commons Attribution License, which permits unrestricted use, distribution, and reproduction in any medium, provided the original author and source are credited. 


\begin{tabular}{|c|c|c|c|}
\hline Tests & Patient's data & Units & Reference ranges \\
\hline Cortisol, AM & 600 & $\mathrm{nmol} / \mathrm{L}$ & $138-690$ \\
\hline ACTH & 42 & $\mathrm{pg} / \mathrm{mL}$ & $<46.0$ \\
\hline $\mathrm{Na}^{+}$ & 140 & $\mathrm{mmol} / \mathrm{L}$ & 136 to 145 \\
\hline $\mathrm{K}^{+}$ & 4.2 & $\mathrm{mmol} / \mathrm{L}$ & 3.3 to 4.8 \\
\hline $\mathrm{Cl}^{\mathrm{a}}$ & 107 & $\mathrm{mmol} / \mathrm{L}$ & 98 to 108 \\
\hline Urea & 26 & $\mathrm{mg} / \mathrm{dL}$ & 12 to 40 \\
\hline Creatinine & 0.9 & $\mathrm{mg} / \mathrm{dL}$ & 0.7 to 1.2 \\
\hline $\mathrm{Ca}^{2+}$ & 9.1 & $\mathrm{mg} / \mathrm{dL}$ & 8.9 to 10.2 \\
\hline Random glucose & 98 & $\mathrm{mg} / \mathrm{dL}$ & \\
\hline $\mathrm{T} 4$ & 17.4 & $\mathrm{pmol} / \mathrm{L}$ & 11.5 to 22.7 \\
\hline T3 & 4.2 & $\mathrm{pmol} / \mathrm{L}$ & 3.5 to 6.5 \\
\hline TSH & 1.8 & $\mu \mathrm{IU} / \mathrm{mL}$ & 0.55 to 4.78 \\
\hline $\mathrm{GH}$ & 0.1 & $\mathrm{ng} / \mathrm{mL}$ & $0-3$ \\
\hline IGF-1 & 220 & $\mathrm{ng} / \mathrm{mL}$ & $163-584$ \\
\hline FAl & 37.8 & & $40-150$ \\
\hline SHBG & 9.0 & $\mathrm{nmol} / \mathrm{L}$ & $9-55$ \\
\hline Testosterone & 3.4 & $\mathrm{Nmol} / \mathrm{L}$ & $9.9-27.8$ \\
\hline FSH & 35 & $\mathrm{mIU} / \mathrm{mL}$ & $1.5-12.4$ \\
\hline $\mathrm{LH}$ & 19.5 & $\mathrm{mlU} / \mathrm{mL}$ & $1.7-8.6$ \\
\hline Prolactin & 230 & $\mathrm{mlU} / \mathrm{mL}$ & $86-324$ \\
\hline B-HCG & $<2$ & $\mathrm{mlU} / \mathrm{mL}$ & $<2$ \\
\hline WBCs & 8.4 & $10^{3} / \mu \mathrm{L}$ & 3.6 to 11.0 \\
\hline $\mathrm{HGB}$ & 13.2 & $\mathrm{~g} / \mathrm{dL}$ & 13 to 18 \\
\hline PLT & 322 & $10^{3} / \mu \mathrm{L}$ & 150 to 400 \\
\hline
\end{tabular}

aACTH: Adrenocorticotropic Hormone; TSH: Thyroid-Stimulating Hormone; GH Growth Hormone; IGF-1: Insulin like growth factor-1; FAI: Free Androgen Index SHBG: Sex Hormone Binding Globulin; FSH: Follicular Stimulating Hormone; LH: Luteinizing Hormone; Na: Sodium; K+: Potassium; Cl: Chloride; Ca: Calciu; T4: Thyroxine; T3: Thyronine; GH: Growth Hormone; B-HCG: Human Chorionic Gonadotrophin Beta. HGB: Hemoglobin; PLT: Platelets; WBCs: White blood cells.

Table 1: Initial investigations.

stretched penile length was $5 \mathrm{~cm}$ with no evidence of hypospadias. The testicular volume was around $4 \mathrm{ml}$ (both sides); they were very soft, and no masses were felt. There were no remarkable finding upon assessment of the cardiovascular, pulmonary, and nervous system examination.

Initial blood investigations are shown in Table 1. Moreover, Seminal analysis revealed marked Azoospermia. Peripheral blood Karyotyping has shown 46,XX, +mar [7], which was further confirmed with FISH tets that revealed $46, \mathrm{XX} / 47, \mathrm{XX},+\operatorname{idic}(\mathrm{Y})$.ish $\operatorname{idic}(\mathrm{Y})(\mathrm{SRY}++)$ as shown in Figure 1.

Ultrasound Scrotum showed both testicles are small in size. The right testis measures $18 \times 9 \mathrm{~mm}$, while the left measures $18 \times 8$ $\mathrm{mm}$. Apparent bilateral homogenous reduction in echotexure, but the vascularity is normal. No evidence of hydrocele or varicocele. Microscopic Testicular Sperm Extraction (TESE) was offered to the patient but he was not willing to accept the procedure. Ultrasound breasts showed normal breast tissue echo pattern; no focal lesions, prominent bilateral subcutaneous fatty tissues, suggestive of pseudogynaecomastia. Ultrasound pelvis showed urinary bladder is normal in outline and contour. No apparent wall thickening or calculus noted. Both inguinal canal regions grossly appear normal. No apparent focal mass lesion noted. No apparent focal area suggestive of Mullerian structures noted in the pelvis or the inguinal area.

\section{Discussion}

To date, no reported cases of SRY 46XX/47XX disorder of sex development, the reported genetic mutations in this field included

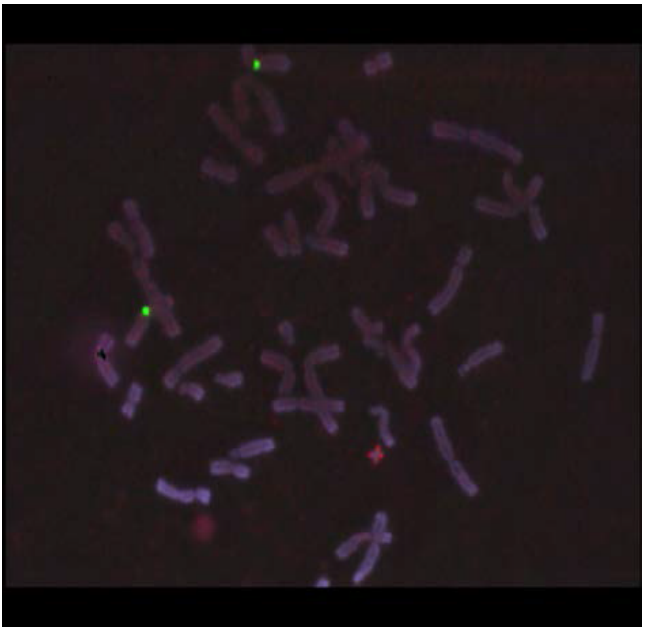

Figure 1: Cytogenetic analysis showed mosaicism for normal 46,XX cells and an abnormal cell line showing $46, \mathrm{XX}$ plus an additional small marker chromosome in $7 / 27$ cells studied. Additional Fluorescence in situ hybridization (FISH) study using SRY gene probe showed the presence of two SRY genes on the small marker chromosome, thus confirming it to be isodicentric $(\mathrm{Y})$ (p10).

In summary it is a case of SRY positive $46, X X$ testicular DSD (or XX male) and the SRY gene is present on the additional isodicentric marker chromosome

46XX/46XY, 46XX/47XXY, 45X/46XY, 46XY, Familial 46XX, AND Non-familial 46XX [4].

Mechanistically, DSD takes place following one of three genetic defects: translocation of $\mathrm{Y}$ on the $\mathrm{X}$ chromosome, gonadal defect, or mosaicism of the gonadal Y chromosome. With an X-linked mutation in the testicular differentiation genes, the earlier two categories usually present with an SRY positive DSD [2].

Though SRY-negative DSD cases are much more rare than SRYpositive cases (1:10) [5], the diagnosis can be provided earlier than the SRY-positive ones, since the delayed virilization of the external genetalia is more apparent in early childhood, and the testicular volume and the penile size hardly increase over time. Moreover the presence of genital ambiguity is much more common in this group [6-8] masculinization can be normal in those individuals, leading to a delayed diagnosis as well (9). Nevertheless, some SRY-positive patients do present with ambiguous genetalia as seen in a few reported cases [8]. urthermore, those individuals can present at a very late stage when they fail to achieve a successful conception, and they attend the fertility clinic as late as 35 and 40 years of age $[9,10]$.

The clinical presentation of these genetic defects varies from full hermaphroditism to completely normal external genitalia. Usually the patients will be diagnosed only at the time of puberty or even after that when they present with features of hypogonadism and infertility [7]. Interestingly, our patient presented relatively late in comparison to the usual presentation time in the reported literature, which is either in early infancy, when the ambiguity of the external genetalia is quite overt, or during puberty [7]. Our case did not have any form of ambiguous genetalia nor short stature.

Biochemically, our patient had a low testosterone and high Gonadotrophins level (FHS and LH), which is the usual scenario in DSD cases. The patients may have normal levels of testosterone during childhood, but these levels diminish at the peri-pubertal age and afterwards [8]. 
Citation: Abdelgadir EIE, Bashier AMK, Alawadi F, Mustafa R, et al. (2015) Late Presentation of a Disorder of Sexual Development Due to Rare 46XX/47XX SRY-Positive 46XX/47XX Karyotype. J Clin Case Rep 5: 541. doi:10.4172/2165-7920.1000541

\section{Conclusion}

Our observation result showed an 18-year-old phenotypical male with female genetics. This was identified as an SRY-positive 46XX/47XX makeup that presented with features of hyper gonadotrophic Hypogonadism. This is our first reported case of an SRY-related 46XX/47XX gene mutation. Thus, clinical screening for this gene has clinical significance for physicians to consider this case.

\section{References}

1. Eggers S, Sinclair A (2012) Mammalian sex determinationâ€"insights from humans and mice. Chromosome Res 20: 215-238.

2. Zenteno-Ruiz JC, Kofman-Alfaro S, Méndez JP (2001) 46,XX sex reversal.

3. Ahmad A, Siddiqui MA, Goyal A, Wangnoo SK (2012) Is 46XX karyotype always a female? BMJ Case Rep 2012.

4. Ozsu E, Mutlu GY, Cizmecioglu FM, Ekingen G, Muezzinoglu B, et al. (2013)
Ovotesticular disorder of sexual development and a rare 46,XX/47,XXY karyotype. J Pediatr Endocrinol Metab 26: 789-791.

5. Gao X, Chen G, Huang J, Bai Q, Zhao N, et al. (2013) Clinical, cytogenetic, and molecular analysis with $46, X X$ male sex reversal syndrome: case reports. J Assist Reprod Genet 30: 431-435.

6. Zenteno JC, López M, Vera C, Méndez JP, Kofman-Alfaro S (1997) Two SRYnegative XX male brothers without genital ambiguity. Hum Genet 100: 606-610.

7. Zenteno-Ruiz JC, Kofman-Alfaro S, Méndez JP (2001) 46,XX sex reversal.

8. Ergun-Longmire B, Vinci G, Alonso L, Matthew S, Tansil S, et al. (2005) Clinical, hormonal and cytogenetic evaluation of $46, \mathrm{XX}$ males and review of the literature. J Pediatr Endocrinol Metab 18: 739-748.

9. Ryan NA, Akbar S (2013) A case report of an incidental finding of a 46,XX, SRY negative male with masculine phenotype during standard fertility workup with review of the literature and proposed immediate and long-term management guidance. Fertil Steril 99: 1273-1276.

10. Valetto A, Bertini V, Rapalini E, Simi P (2005) A 46,XX SRY-negative man with complete virilization and infertility as the main anomaly. Fertil Steril 83: 216219 